\title{
A formação do dalang em Bali: o marionetista no teatro de sombras wayang kulit
}

The apprenticeship of the dalang in Bali: the shadow theater wayang kulit's puppeteer

Juliana Coelho de Souza Ladeira ${ }^{1}$ 


\section{Resumo}

O wayang kulit, o teatro de sombras de Bali é uma forma espetacular herdeira da tradição indobudista vinda de Java, no século XV, e um dos responsáveis pela indianização de Bali, através da utilização dramatúrgica das epopeias indianas. $O$ processo de formação do dalang, o marionetista, é complexo, abrangendo um extenso aprendizado literário, linguístico, ritualístico e vocal. O dalang deve articular os mitos ancestrais e a contemporaneidade, transmitindo ensinamentos filosóficos e religiosos, além de comentar aspectos da sociedade atual.

Palavras-chave: Wayang; Bali; teatro de sombras; dalang; voz

\section{Abstract}

The wayang kulit, the shadow theater of Bali, belongs to the Indo-Buddhist tradition, that came from Java in the fifteenth-century, and is one of the responsible for the indianization of Bali, by the use of Indian epics. The formation process of the dalang, the puppeteer, is complex, encompassing an extensive literary, linguistic, ritualistic and vocal learning. The dalang must articulate the ancestral myths and the contemporaneity, dispensing philosophical and religious teachings and commenting aspects of the society as well.

Keywords: Wayang; Bali; shadow theater; dalang; voice 
Em Bali, assim como em quase todo arquipélago indonésio, o marionetista-narrador é denominado dalang. Ele é uma figura central nas artes cênicas desta região, sendo a arte do marionetista em Bali designada pelo termo pedalangan. Durante minhas pesquisas de campo em Bali, tive contato direto com dois marionetistas do vilarejo de Singapadu. Um deles, I Ketut Kodi, é dalang, ator-dançarino de topeng ${ }^{2}$ e escultor de máscaras. A outra, Ni Nyoman Candri, é reconhecida em toda a ilha como intérprete de arja ${ }^{3}$, além de ser uma das poucas mulheres a ter sido iniciada no wayang kulit e no topeng, duas formas espetaculares tradicionalmente masculinas. Os depoimentos destes e de outros artistas balineses constituirão a base para esta apresentação e análise da formação do dalang em Bali.

\section{O wayang kulit}

Entre os séculos XIII e XV, grande parte do arquipélago que hoje constitui a Indonésia foi dominado pelo império indobudista javanês Majapahit. Nesse contexto de expansão javanesa, Bali foi invadida e conquistada por Majapahit por volta do século XIV. No final do século XV, fugindo do avanço islâmico em Java, a corte real e seus seguidores se transferiram em massa para Bali. O wayang kulit faz parte das formas espetaculares balinesas herdeiras da tradição indobudista originárias de Java e do Império Majapahit. A tradição do wayang pode ser encontrada em toda região do arquipélago indonésio que possui herança indobudista. Reconhecidas como aristocráticas (Basset, 1993, p. 63), essas formas espetaculares transplantadas pela corte javanesa em Bali foram fundamentais para a quase completa indianização da ilha (Picard, 2012), uma vez que as epopeias indianas se tornaram o modelo cultural e religioso da população balinesa e foram incorporadas como marcos históricos fundadores. Porém, a tradição do wayang parece ser ainda mais antiga em Bali, pois as primeiras inscrições do termo wayang aparecem em 863 d.C. no texto prasasti Bebetin e uma menção ao termo dalang está presente em um escrito de 1053 d.C., prasasti Dawan, indicando que o teatro de formas animadas possa ter uma origem muito mais antiga em Bali (Dibia; Ballinger; Anello, 2004, p. 109).

20 topeng é uma forma espetacular balinesa, dançada e interpretada com máscaras.

3 A arja é uma forma espetacular balinesa, cantada e dançada, popularmente chamada no exterior de "opera cômica". 


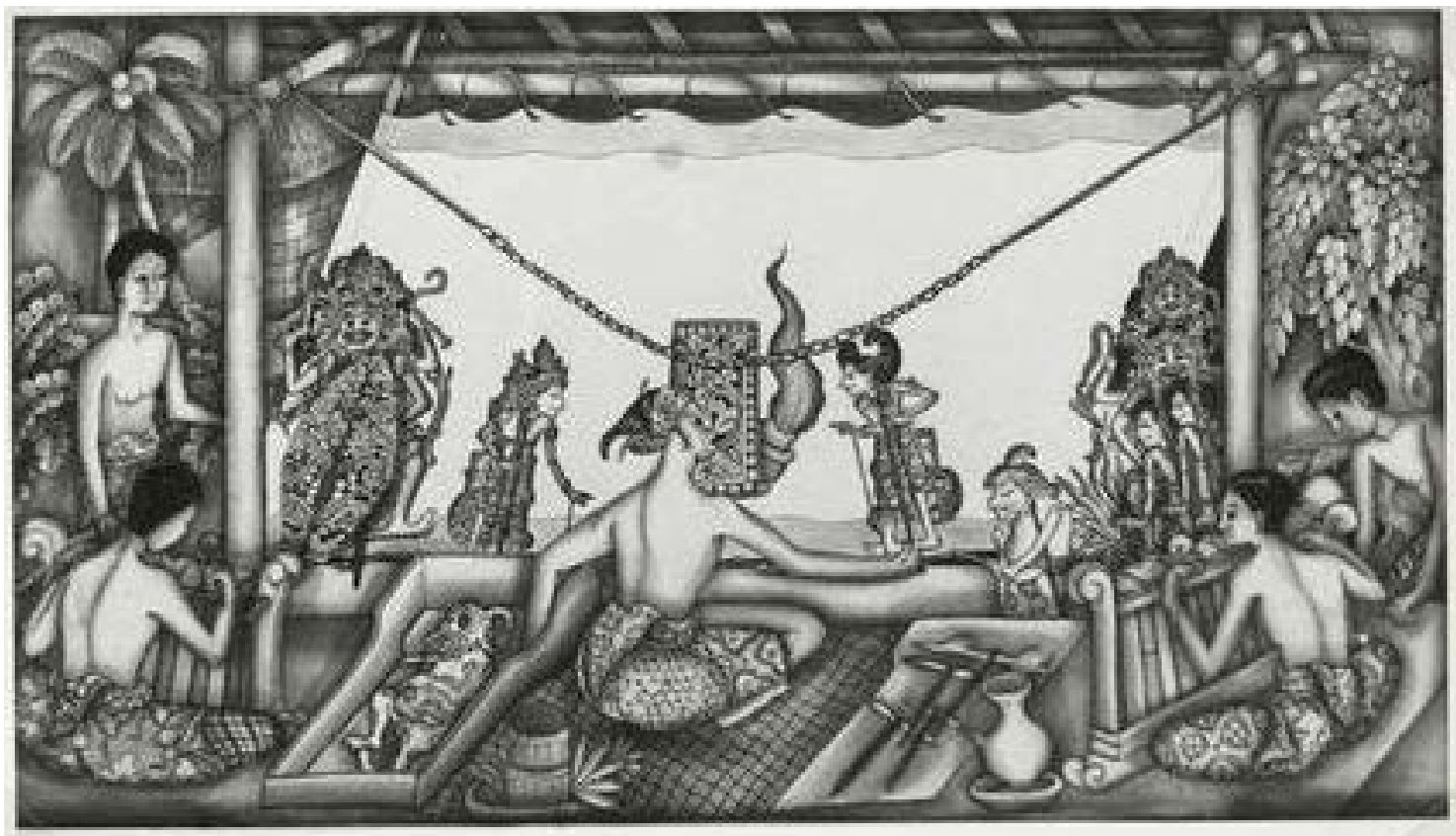

Pintura tradicional de uma apresentação de wayang kulit. Autor: desconhecido. Fotógrafo: A. Hudson. Fonte: Jerome Robbins Dance Division, The New York Public Library. ${ }^{4}$

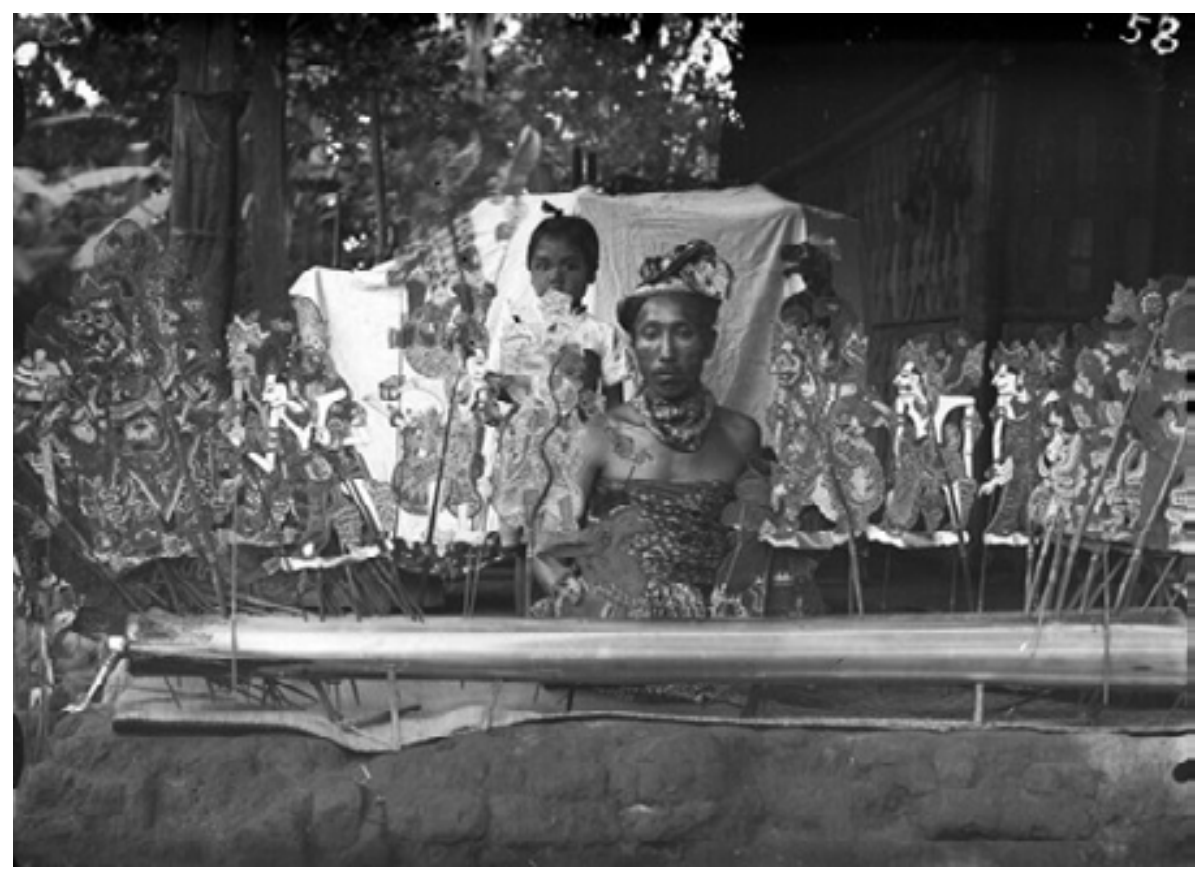

Fotografia antiga de uma apresentação de wayang kulit lemah, conduzida pelo dalang brâmane Ida Putu Sweca (data desconhecida, entre 1910 e 1925). Fotógrafo: desconhecido. Fonte: Tropenmuseum collection online ${ }^{5}$

A palavra wayang designa o teatro de sombras. Pode ser traduzida também como "sombra" e num sentido filosófico mais amplo, como "aparências". Kulit significa "couro". De fato, as marionetes utilizadas nessa forma espetacular são planas, confeccionadas

4 Alfred Hudson. Photograph of painting of Balinese wayang kulit [1860-1969?]. 1 fotografia, p\&b. Disponível em: <https://digitalcollections.nypl.org/items/510d47dc-4aa2-a3d9-e040-e00a18064a99>. Acesso em: 01 jul. 2018.

5 De poppenspeler Ida Putu Sweca uit Banjar met zijn wayang kulit poppen [1910-1925?]. 1 fotografia, p\&b. Disponivel em: <https://hdl.handle. net/20.500.11840/323738>. Acesso em: 01 jul. 2018. 
e esculpidas através de perfurações no couro de búfalo e posteriormente pintadas e adornadas dos dois lados ${ }^{6}$. Algumas marionetes têm o maxilar móvel, o que lhes permite uma expressividade mais acurada do ato de falar. Elas são consideradas como receptáculos de vida. A arte do wayang é profundamente ancorada na base religiosa arcaica e animista de Bali, na qual todos os materiais do mundo têm intrinsecamente uma forma de vida.

A primeira apresentação ${ }^{7}$ de wayang kulit que assisti ocorreu durante as festividades do galungan ${ }^{8}$, no vilarejo de Mas, em 2008. Como acontece com as apresentações de wayang kulit noturnas, começou tarde da noite, depois das 22 horas. No pátio exterior do templo, alguns homens e mulheres já estavam sentados no chão, conversando diante de um pequeno pavilhão. Crianças andavam para todos os lados, algumas dormiam no colo de seus pais e avós. Aos poucos, o dalang (marionetista) chega a esse pavilhão. Ele começa a se preparar, executando um conjunto elaborado de ações preliminares, instalando um pano branco (kelir) que servirá de tela e realizando as primeiras oferendas, que serão descritas brevemente a seguir. Após esses preparativos iniciais, uma lâmpada de óleo de coco (damar) foi acesa. Os músicos do gamelan Gender Wayang se posicionam atrás do dalang, escondidos pelo grande pano branco. De repente, o som suave das percussões metálicas do gamelan ecoa no meio do ambiente polifônico do exterior do templo. Toda forma espetacular balinesa, clássica ou contemporânea, é acompanhada pelo gamelan, comumente descrito como "orquestra" de percussões metálicas. O gamelan pode ser melhor compreendido dentro do conceito de instrumento coletivo, pois seus instrumentos ${ }^{9}$ não podem ser tocados separadamente, mas sempre coletivamente (Basset, 1995).

O dalang também conduz o gamelan: ele tem um tipo de martelo (cepala), entre os dedos dos pés, com qual ele bate a caixa de madeira (kropak) onde dormem as marionetes. Além da percussão, o dalang conduz os músicos do gamelan Wayang Gender através do movimento das marionetes e da voz (Foley; Sedana, 2005, p. 52). Em uma apresentação, os dançarinos, cantores, atores e marionetistas precisam kawin dengan musik, "se casar com a música".

Como dizem os balineses, é hora das marionetes acordarem, respirarem e tornarem-se vivas. Não existe uma convecção rígida ou formal entre a apresentação e o público. Espera-se o respeito, mas também se permite a liberdade. Assim, uma parte do público pode se dirigir para detrás da tela e apreciar a apresentação deste local.

\footnotetext{
60 registro audiovisual Generations of Shadows mostra algumas imagens do processo de confecção das marionetes do wayang kulit, além de um breve depoimento do escultor I Wayan Kurdana. Disponível em: <https://www.youtube.com/watch?v=7TvLsyek1SE>. Acesso em: 01 jul. 2018.

7 Os registros que realizei desta apresentação não contemplaram a diversidade de elementos do wayang kulit. Por isso, selecionei alguns vídeos disponíveis na internet para facilitar a compreensão do leitor. O vídeo Wayang Kulit/ Shadow Puppet Theatre é o registro de uma apresentação com os dalang I Made Gender e I Ketut Pasek. Nele, a configuração do espaço do dalang e sua movimentação estão bem ilustrados. Disponível em: <https://www.youtube.com/watch?v=CRdWhZJUGkA>. Acesso em: 01 jul. 2018. - No vídeo, Wayang Kulit/ Shadow Play/ Théâtre d'ombres, observa-se a configuração do espaço cênico, dos músicos e do dalang. Este realiza os diálogos em inglês, especialmente para a filmagem. Apesar de não ser uma apresentação do repertório tradicional do wayang kulit, 0 registro é precioso por mostrar com clareza a movimentação das marionetes. Disponível em: <https://www.youtube.com/watch?v=U6eD17MqRwE>. Acesso em: 01 jul. 2018.

8 Durante os dez dias do festival chamado galungan, toda a ilha de Bali é tomada por celebrações religiosas e apresentações espetaculares. Galungan é o nome dado ao primeiro dia das festividades e kuningan, ao último. Outros festivais importantes em Bali são os odalan, celebrados em todos os templos da ilha e marcam o início/final do ciclo de um ano do calendário balinês chamado pawukon. Os odalan correspondem ao "aniversário" do templo, ocasião na qual as divindades vêm habitar as estatuetas presentes em alguns de seus altares mais importantes. Um ano do calendário pawukon corresponde a 210 dias do calendário gregoriano.

9 Existem diferentes configurações de gamelan em Bali, formadas principalmente por xilofones metálicos de diversos tamanhos, tambores condutores, flautas, entre outros instrumentos.
} 


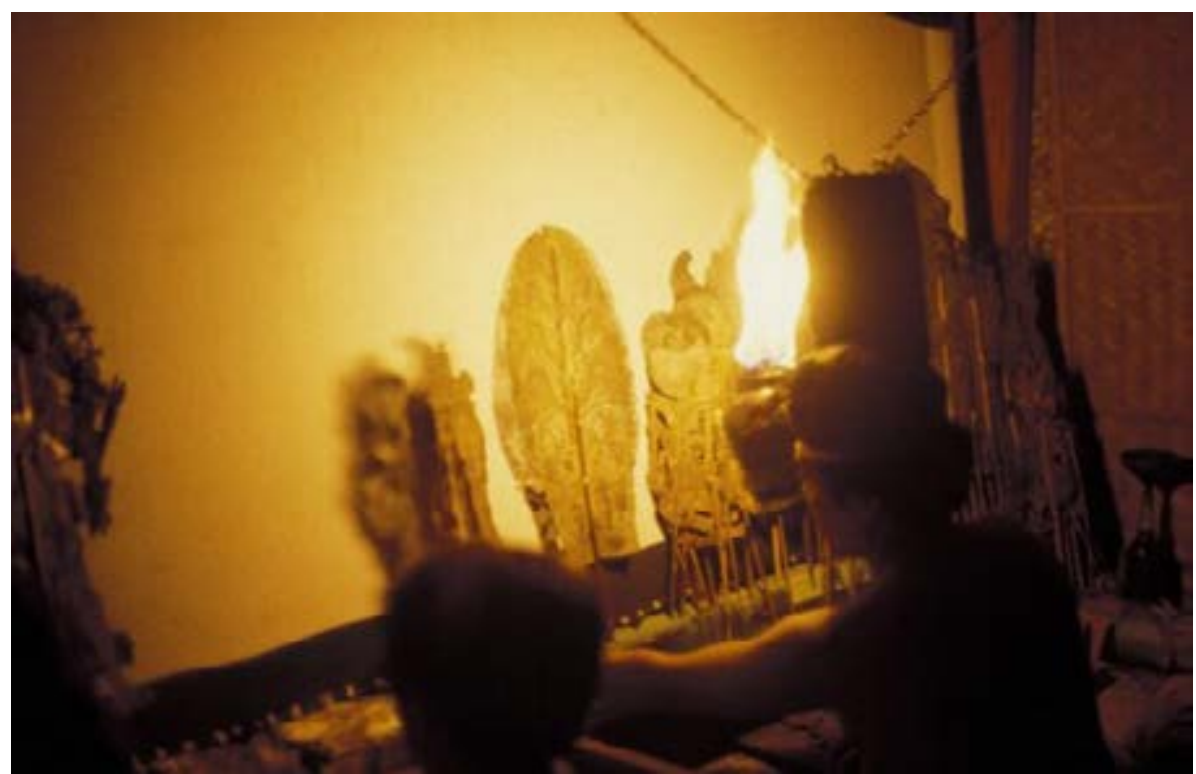

Apresentação de wayang kulit durante a cremação do príncipe Cokorda Gede Agung Sukawati (1979), no vilarejo de Ubud. Fotógrafo: W.L.J. van Gessel. Fonte: Tropenmuseum collection online ${ }^{10}$

A configuração do palco e a disposição de todos os elementos do wayang kulit têm uma correspondência simbólica e mística com a cosmologia esotérica balinesa: a tela (kelir) é o símbolo do universo. É também o limiar entre os mundos visíveis (sekala) e invisíveis (niskala). A kelir é amarrada em sua base a um tronco de bananeira (gedebong) e nele as marionetes são dispostas e cravadas em orifícios. O gedebong corresponde à deusa Pertiwi, à Terra-Mãe. As cordas que esticam a tela representam os tendões e músculos humanos, enquanto o damar, a lâmpada de óleo de coco, simboliza o sol. Esta é amarrada com três linhas diferentes, correspondendo à tríade hindu Brahma, Vishnu e Shiva (Dibia; Ballinger; Anello, 2004, p. 109). Essas ações fazem parte de um protocolo específico, chamado pamungkah (Sedana; Foley, 1993, p. 98) que deve ser realizado no início da apresentação. Primeiramente, o dalang pronuncia alguns encantamentos (mantras) e realiza gestos sagrados (mudras). Em seguida, abre a caixa que guarda as marionetes (kropak) e dispõe as mesmas em seus lugares apropriados. Os personagens nobres e bondosos são colocados no lado direito e os outros à esquerda, fincados ao gedebong.

A primeira marionete a tornar-se viva e a dançar é a kayonan, uma figura triangular abstrata que simboliza a natureza em sua globalidade, a árvore da vida. Essa primeira dança representa a criação do universo e seus cinco elementos clássicos. A kayonan retornará no final, sendo a última marionete da apresentação. O início e o fim de uma apresentação de wayang kulit serão sempre os mesmos.

10 W.L.J. Van Gessel. Wayang kulit voorsterlling in de puri, een avond voorafgaand aan de crematie van Cokorda Gede Agung Sukawati [1979]. Disponível em: $<$ <ttps://hdl.handle.net/20.500.11840/485443>. Acesso em: 01 jul. 2018. 


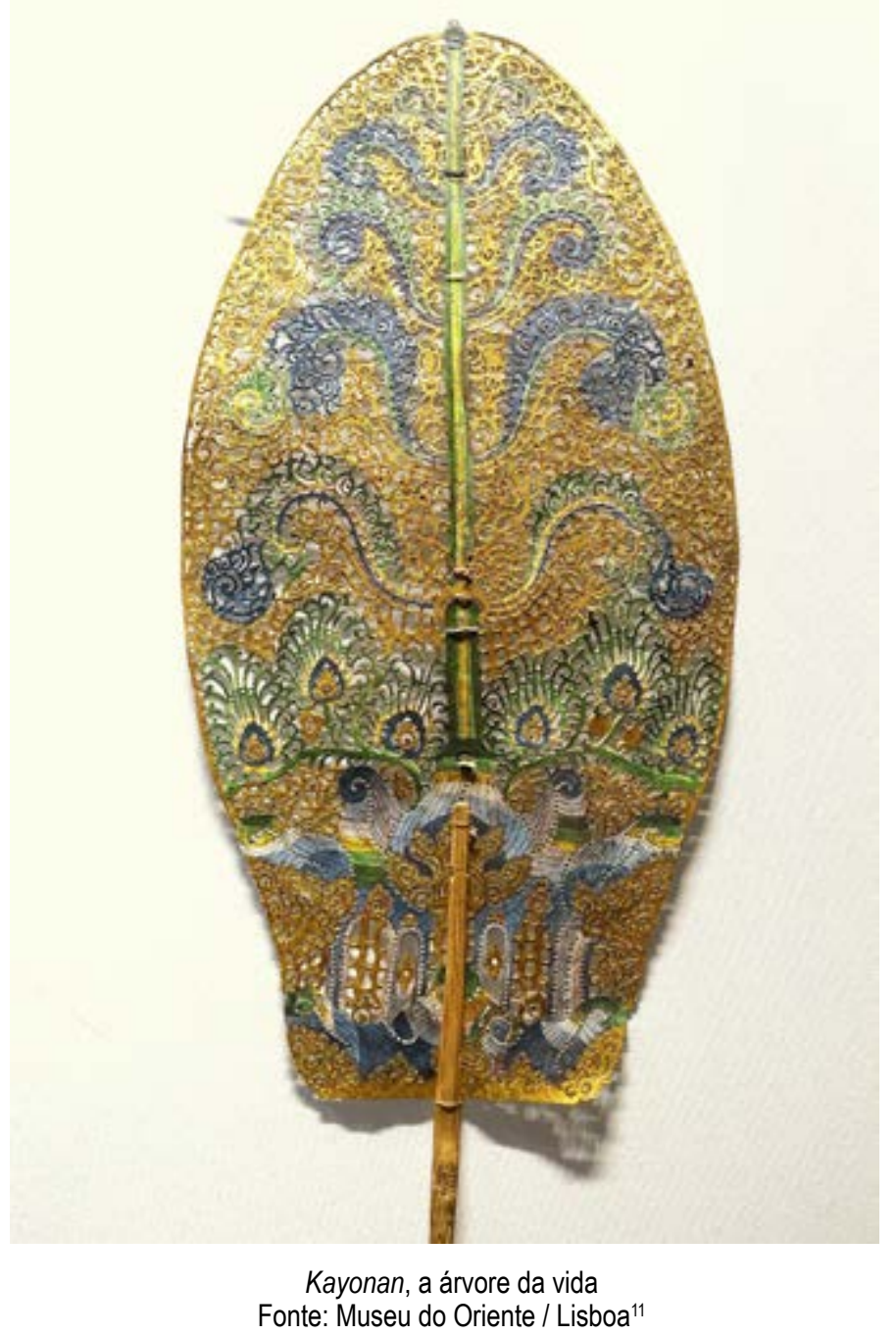

\section{As variações do repertório dramatúrgico do wayang kulit}

A principal base literária do wayang kulit são as epopeias hindus Mahabharata e Ramayana. Essas epopeias foram adaptadas pelos javaneses e escritas em kawi ${ }^{12}$, ou javanês arcaico. As histórias mais adaptadas do Mahabarata são as do Bhatara Yurdha: a grande guerra entre os primos Padawas e Kurawas. O prólogo do Mahabharata, os livros conhecidos como Adipawas, é fundamental para o dalang (Spies; De Zoete, 2002 p. 293). Os episódios do Ramayana mais utilizados são o sequestro de Sita e a batalha do exército de macacos, chefiadas por Hanuman. Os intelectuais balineses continuaram a utilizar o kawi, que se tornou a língua da aristocracia e dos personagens nobres - também em outras formas espetaculares, como no gambuh e no topeng. Em Bali, o kawi tem uma métrica que facilita o canto e, por isso, é apresentado dessa maneira em cena. No entanto, em cada apresentação de wayang kulit será criada uma interpretação sempre original dos escritos e da tradição oral.

\footnotetext{
11 Kayonan. [?].1 fotografia, color. Disponivel em: <https://commons.wikimedia.org/wiki/File:Unidentified,_Wayang_Kulit,_Bali_-_Museu_do_Oriente_-_Lisbon,_ Portugal_-_DSC06827.JPG>. Acesso em: 01 jul. 2018.
}

12 Existe uma grande equivalência entre o sânscrito e o kawi. Este também significa "poeta" em balinês (Corbarruvias, 2008, p. 216) 
Logo após a saída da kanyoan, a árvore da vida, o dalang poderá seguir duas linhas dramatúrgicas: ou ele cantará o penyacah parwa, o prólogo em kawi para o Mahabharata ou o purwa kanda, o prólogo para uma história do Ramayana. Essa passagem vocal e instrumental é chamada alas harum ("floresta perfumada") e é o acompanhamento para a entrada em cena dos personagens nobres e seus servidores. Os personagens representados correspondem aos das epopeias acima citadas (Sedana; Foley, 1993, p. 98).

Uma característica das formas espetaculares balinesas e também do wayang kulit é a de incorporar um duo de servidores cômicos, chamado punakawan, que conduzem a história que vai ser contada. Uma de suas importantes funções na apresentação é a atuarem como tradutores dos personagens nobres. Uma vez que esses últimos se expressam em kawi, os punakawan são os responsáveis pela vernaculização do conteúdo filosófico fundamental para a ocasião, além de propiciarem grande parte do conteúdo cômico, por meio da atualização e da contextualização do enredo para os dias de hoje. No wayang kulit, o duo cômico dos personagens virtuosos são Twalen ${ }^{13}$ e Merdah, enquanto os servidores dos personagens maléficos são Sangut e Delem. Condong, a criada da rainha (putri), também pode estar presente nas apresentações.
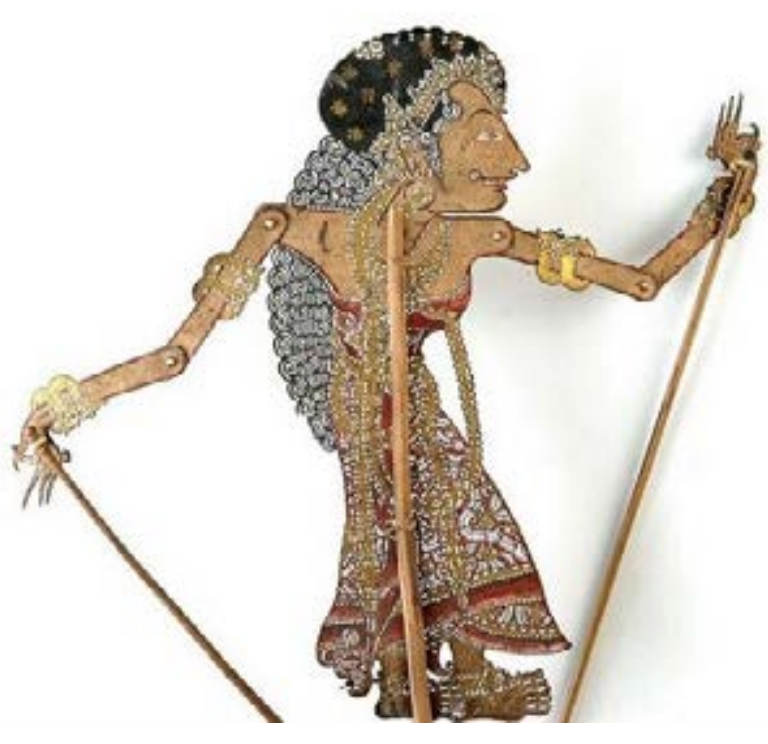

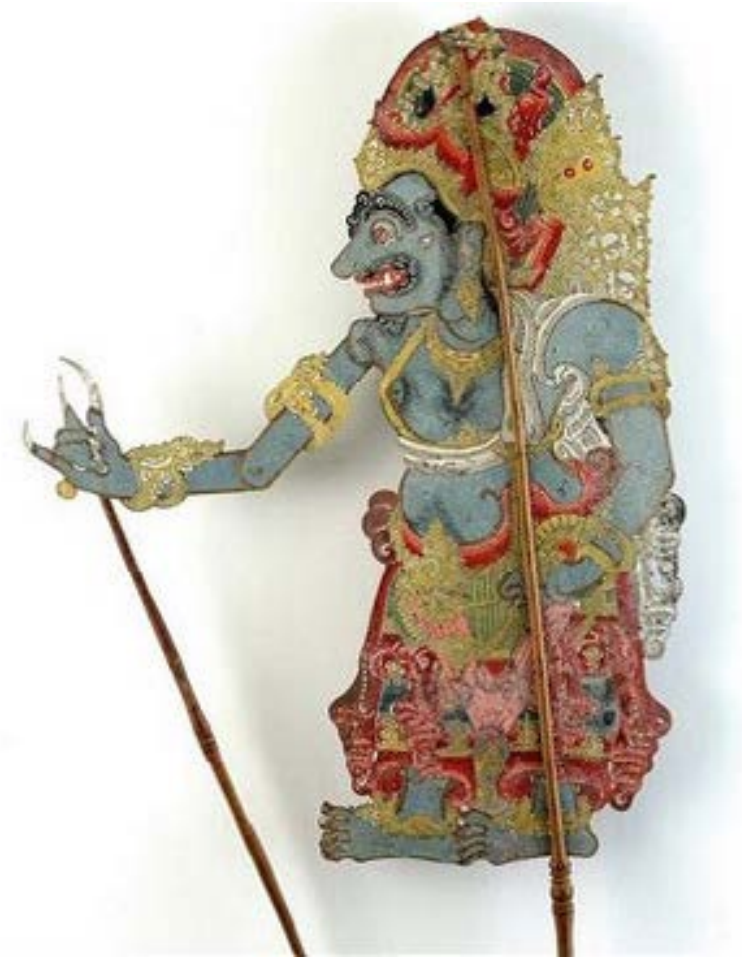

Arjuna $^{14}$ e Vishnu ${ }^{15}$

Fonte: Tropenmuseum collection online (1)

13 Twalen é chamado também de Malen. Para os balineses, ele teria sido criado da poeira do corpo de Sanghyang Tunggal (o Deus Supremo) e teria sido convo-
cado a morar entre os humanos virtuosos. Ele é fonte de conhecimento e possui um terceiro olho que indica sua introspecção e sabedoria. Ele é pai de Merdah. (Dibia; Ballinger; Anello, 2004, p. 112)

14 Wayangfiguur voorstellende Subadra, de demalin van Arjuna[?].1 fotografia, color. Disponível em: <https://hdl.handle.net/20.500.11840/181131>. Acesso em: 01 jul. 2018. 

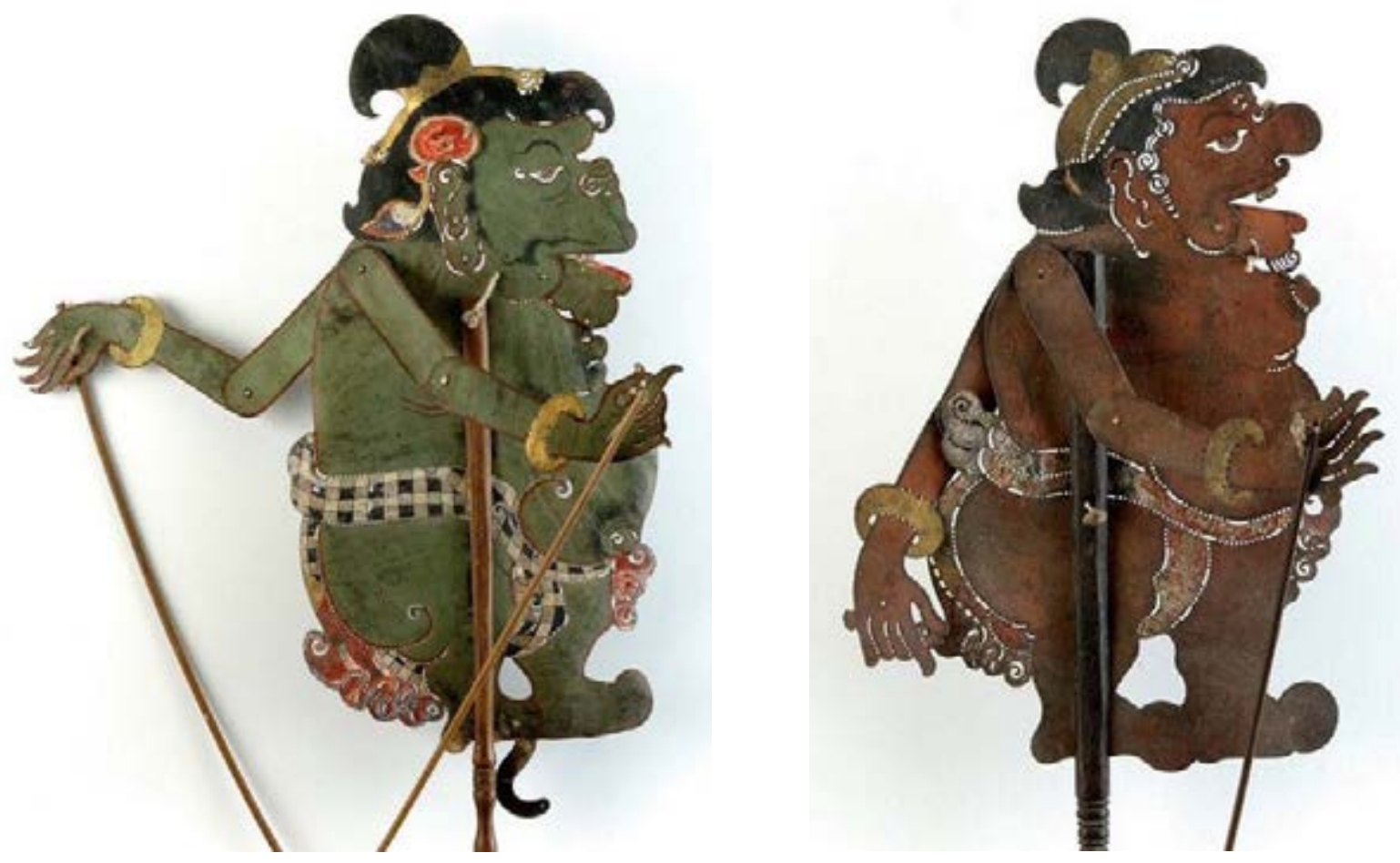

Twalen $^{16}$ e Merdah $^{17}$

Fonte: Tropenmuseum collection online
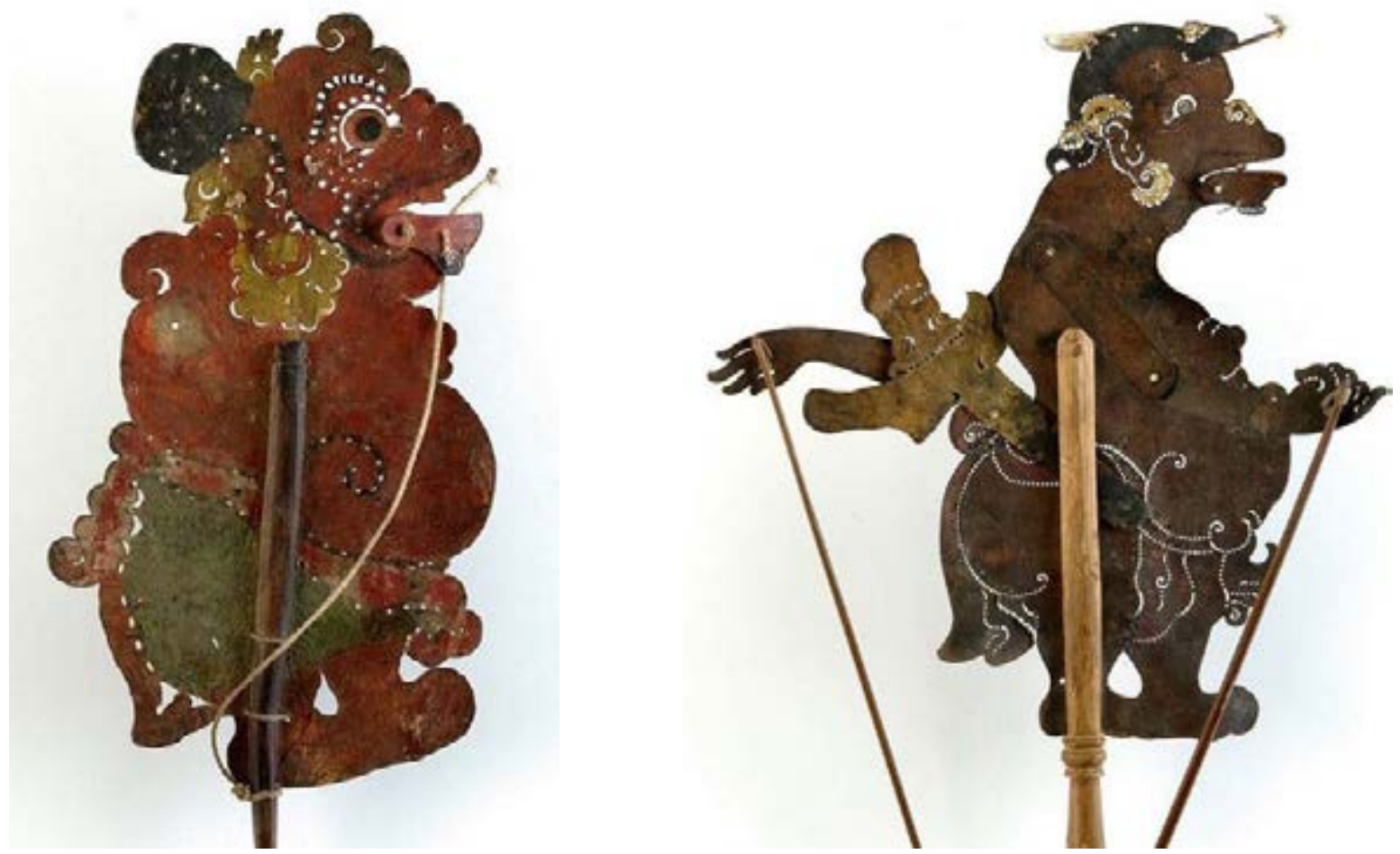

Sangut ${ }^{18}$ e Delem ${ }^{19}$

Fonte: Tropenmuseum collection online

16 Wayangfiguur voorstellende de clown en bediende Twalen [?].1 fotografia, color. Disponivel em: <https://hdl.handle.net/20.500.11840/181174>. Acesso em: 01 jul. 2018.

17 Wayangfiguur voorstellende de clown en bediende Mredah [?].1 fotografia, color. Disponivel em: <https://hdl.handle.net/20.500.11840/181177>. Acesso em: 01 jul. 2018.

18 Wayangfiguur voorstellende de clown en bediende Sangut [?].1 fotografia, color. Disponivel em: <https:/hdl.handle.net20.500.11840/181178>. Acesso em: 01 jul. 2018

19 Wayangfiguur voorstellende de clown en bediende Delem [?].1 fotografia, color. Disponível em: <https://hdl.handle.net20.500.11840/181179>. Acesso em: 01 jul. 2018. 
É importante destacar que na ilha, o discurso espetacular pode se revestir das mais variadas funções de enunciação: por vezes portadoras de ensinamentos filosóficos e religiosos, de reivindicação e crítica social, além de ser um meio de articulação dos mitos ancestrais com a contemporaneidade. Dessa forma, além de muita criatividade (perkembangan), espírito inteligente e rápido, o dalang precisa estar conectado com o cotidiano ao seu redor. Em um artigo de 1979, Frederik DeBoer observa o reconhecido dalang I Nyoman Rajeg, ou Pak (Pai) Rajeg:

[...] o seu campo de referência não tem sido o de um simples aldeão que conhece apenas as preocupações da sua própria localidade, mas o de um cidadão moderno da Indonésia que é muito consciente do mundo fora de Bali, lendo os jornais e ouvindo as notícias no rádio. Em sua apresentação de wayang, ele é capaz de relacionar de maneira vital as situações arquetípicas da literatura tradicional com eventos contemporâneos e preocupações oportunas de seu público. Ao fazê-lo, ele continua a cumprir as responsabilidades consagradas ao dalang como professor e conselheiro da população (Deboer, 1979, p. 60-61) ${ }^{20}$.

Os personagens cômicos punakawan constroem essa ponte entre o mundo sagrado dos personagens arquétipos e o mundo cotidiano e tangível dos balineses. No que diz respeito às temáticas abordadas, esse encadeamento é traçado pela incorporação de assuntos da ordem do dia. A conexão entre mundos também se dá por meio do exercício contínuo da tradução ao longo de uma apresentação. Com efeito, é por meio dessa vernaculização do repertório das epopeias indianas que as formas espetaculares balinesas se tornaram veículo de transmissão da sabedoria e do modelo hindu. Podemos considerar os pares cômicos punakawan como verdadeiras pontes entre a Índia e Bali (Picard, 2012).

\section{O wayang kulit cerimonial ou lemah}

O wayang kulit tem diversas classificações, mas duas delas são preponderantes a todas as outras: wayang kulit e wayang kulit lemah, que são, respectivamente, apresentados à noite e durante o dia. O wayang noturno tem funções de entretenimento explícitas, enquanto o wayang lemah estará sempre relacionado e sintonizado com determinado rito, dentro de um contexto cerimonial amplo. Desta divisão de propósitos, deriva também a diferença do repertório abordado pelo dalang, pois durante a noite, a apresentação será direcionada a um público humano. A presença do público humano para o wayang lemah é totalmente irrelevante, pois ele acontece misticamente no plano dos deuses, onde as luzes (lemah) são eternas. Assim, a história a ser abordada terá prioritariamente uma relação direta com a cerimônia na qual o wayang lemah se insere, enquanto que no wayang noturno, o dalang terá mais liberdade para relacionar ou não sua apresentação com o contexto geral no qual ele está incluído. Os mitos escolhidos pelo dalang no wayang lemah enquadram-se dentro de uma ocasião social ampla e priorizam, por exemplo, o repertório de histórias do Adiparwa (Hobart, 1987, p.

20 "However, his frame of reference has not been that of a simple villager who knows only the concerns of his own locality, but that of a modern citizen of Indonesia who is very much aware of the world outside Bali, reading the newspapers and listening to the news broadcasts. In his wayang performance, he is able to bring the archetypical situations from the traditional literature into vital relation to contemporary events and the timely concerns of his audience. In so doing, he continues to fulfill the dalang's time-honored responsibilities as teacher and counselor of the populace." (Tradução nossa) 
43). Além disso, ele será apresentado em um local de maior sacralidade e não no pátio exterior do templo.

Além do Mahabharata e do Ramayana, o wayang kulit noturno pode se inspirar em outras bases literárias, encontrando correspondências em outras formas espetaculares de Bali, tais como: wayang gambuh, wayang calonarang, wayang arja ${ }^{21}$, wayang cupak, wayang sasak, além de formas que surgiram dentro das universidades, a exemplo de: wayang babad e wayang layar lebar.

\section{A pluralidade linguística}

Durante uma apresentação de wayang kulit, assim como num conjunto amplo de formas espetaculares balinesas, diversas línguas são empregadas pelo dalang. Os personagens eruditos da elite aristocrata se expressam em kawi, língua que corresponde ao javanês arcaico e no extrato erudito do balinês. O kawi é a marca da aristocracia. Os personagens cômicos se expressarão nas duas línguas acima, quando em diálogo com os personagens nobres. Por sua vez, eles falarão entre si e se dirigirão ao público em balinês médio, em indonésio e, se a ocasião for propícia, em inglês ou mesmo em outra língua estrangeira.

\section{O sentido e a função do dalang: o marionetista sacerdote}

"O dalang é um artista e um grande professor espiritual" (Covarrubias, 2008, p. 219) ${ }^{22}$. Criador do universo em cena, com todas as suas batalhas e vitórias, o dalang é o ponto de ligação na Terra do Deus supremo, o Grande Dalang. O wayang kulit pode ser considerado uma das formas espetaculares mais imbuídas de poder sagrado em Bali. Além de toda a sua formação literária, técnica, musical e vocal, o dalang também é introduzido a conhecimentos esotéricos e religiosos que fazem com que ele tenha a equivalência de um sacerdote. Assim, ele é autorizado a consagrar a água (tirta), algo fundamental para a totalidade de ritos e oferendas balinesas ${ }^{23}$ (Deboer, 1979, p. 60). Seu serviço sacerdotal funde-se com a sua função performativa no wayang kulit lemah, durante uma apresentação denominada murwakala:

O dalang combate Batara Kala durante as apresentações chamadas murwakala do Wayang, que significa "enviar o tempo a sua origem (purwa)". Wayang é uma palavra que significa aparências, estas são devidas ao véu de Maia. As vítimas de Kala são os humanos nascidos como Kala, na semana denominada Wayang do calendário divinatório Pawukon. É durante essa semana de aniversário que acontecem os "endocirsmos" murwakala, o contrário de um exorcismo, uma vez que purificar é sempre enviar ao centro. (Basset, 2010, p. 50) 24 $^{24}$

\footnotetext{
210 curta metragem Wayang Arja pode ser assistido no link disponibilizado a seguir. Nele, o renomado marionetista I Made Sidja conta brevemente a invenção do wayang arja. Disponível em: <https://www.youtube.com/watch?v=apc-8EYuG6I>. Acesso em: 1 de jul. 2018. Em outro vídeo, o programa web, BALI GO LIVE. Stories of Balinese Wayang Maestro "I Made Sidja", o mesmo dalang disserta sobre sua história. Disponível em: <https://www.youtube.com/watch?v=Ad3INKDyOrg>. Acesso em: 1 de jul. 2018.

22 "The dalang is an artist and a great spiritual teacher." (Tradução nossa)

23 Nesse artigo de 1979, Frederik deBoer traça um perfil interessantíssimo de I Nyoman Rajeg ou Pak Rajeg, um reconhecido dalang balinês, pertencente a uma geração que cresceu sob a colonização holandesa.
}

24 "Le dalang combat Batara Kala au cours des représentations nommées murwakala ("renvoyer le temps à l'origine purwa") du Wayang, un mot qui signifie apparences, 
Batara Kala, gerado pelo esperma de Shiva, é o Tempo, um monstro gigante, devorador insaciável dos humanos. Em Bali, as pessoas que nascem na semana Wayang são cobertas de mau agouro, como se destinadas a aplacar a fúria de Batara Kala. Portanto, é para elas que as apresentações de murwakala são conduzidas.

\section{O aprendizado das oferendas}

Nas formas espetaculares balinesas, o aprendizado da confecção e de qual oferenda é propícia para cada ocasião é tão fundamental quanto o aprendizado técnico da forma em si. No wayang kulit, o dalang tem suas próprias marionetes. $\mathrm{O}$ aprendiz à dalang deve passar por uma cerimônia denominada mekawin/menunggal, onde ele se "casa" com suas marionetes. O aprendizado das oferendas e de todo o processo ritualístico a ser feito antes e depois de uma apresentação de wayang fazem parte do processo de ensino-aprendizagem do dalang. As principais oferendas destinadas às marionetes e aos instrumentos musicais são: bakaran ("queimado") que designa a carne crua ou a galinha viva que é enviada à casa do dalang antes de uma apresentação. No início da apresentação, duas oferendas são feitas: uma para os deuses, a santun pemungkah ("a essência do abrir"), constituída de coco, ovo, arroz, flores, dinheiro, incenso e água (tirta), e outra para os buta-kala ${ }^{25}$, denominada segehan ("alimentar"), que inclui vinho de arroz e de palma, água (tirta), arroz, flores e incenso (Sedana; Foley, 1993, p. 98). As oferendas podem variar e se tornarem mais elaboradas de acordo com a importância da cerimônia. Para algumas delas, apenas um dalang experiente e iniciado em práticas mais complexas é autorizado a se apresentar.

\section{A formação do dalang}

Como dito anteriormente, a arte do wayang é chamada pewayangan e a do marionetista, pedalangan. Devido a toda mestria de improvisação oral articulada em discurso, tradução e canto que é exigida de um dalang, a arte do wayang é certamente a mais difícil das formas espetaculares balinesas. O livro fundamental do aprendiz é o Darma Pewayangan"26, "Sabedoria e Encantamentos do Wayang", (Hooykaas, 1973). Outras obras importantes são o Niti Sastra (Literatura da Obediência) e o Sarasamuscaya (Essência do Conhecimento Divino), que abordam preceitos de conduta diária do dalang. Além disso, os clássicos Mahabharata e Ramayana em prosa (parwa) ou em versos metrificados (kekawin) são leituras norteadoras, além das crônicas balinesas Babad e das histórias do príncipe Panji, reunidas no Malat.

O processo de ensino-aprendizagem padrão em Bali é centrado na dinâmica de exposição do professor seguida da repetição do aluno. O aprendiz aborda um

\footnotetext{
ces dernières étant dues au voile de Maya. Les victimes désignées de Kala sont principalement des humains nés comme Kala dans la semaine nommée Wayang du calendrier divinatoire Pawukon et c'est dans cette semaine anniversaire qu'ont lieu les "endorcismes" murwakala, le contraire d'un exorcisme puisque purifier est toujours recentrer." (Tradução nossa)

25 Os buta-kala são os seres fragmentados e maléficos do mundo invisível (niskala).

26 Na obra Kama and Kala: Materials for the study of Shadow theatre, Christiaan Hooykaas compilou cerca de 16 manuscritos do Darma Pewayangan, oriundos de diversas partes da ilha, e os traduziu para o inglês. A obra discorre também sobre as funções ritualísticas do dalang.
} 
conjunto de movimentos, ações e danças das marionetes, em concomitância com o treino de discursos, canções e diálogos padrões. Essas cenas-padrão são compostas pelas narrações em canto que apresentam os personagens nobres, cenas de amor, cenas tristes e batalhas (Sedana; Foley, 1993, p. 82). O aprendiz tem um repertório de base, mas toda a articulação dramatúrgica e o embelezamento da história depende de cada um:

Seu professor lhe oferece um modelo com diálogos e cenas padrão, mas você deve aprender como adaptá-los à miríade de lakon [histórias] do repertório. Você aprende macetes ao assistir seu professor e outros dalang, mas o trabalho real da história e seu desempenho bem-sucedido dependem da sua própria habilidade e criatividade (Sedana; Foley, 1993, p. 82) ${ }^{27}$.

Para sua primeira apresentação pública, provavelmente, o futuro dalang será convidado a um evento de menor importância, para que dele não seja exigido um conhecimento variado do repertório do wayang kulit.

\section{O aprendizado em família}

Frequentemente, o conhecimento do pedalangan, da arte do dalang, é transmitido de pai para filho ou de avô para neto - trata-se de uma forma cênica essencialmente masculina. Desde pequeno, o aprendiz acompanhará o pai ou o avô nas diversas cerimônias como ajudante, observará as aulas na propriedade familiar e participará de conversas informais sobre o repertório do wayang, sobre a filosofia balinesa e outros tantos temas. Caso um jovem que não seja de uma família de dalang se interesse pelo wayang kulit, ele terá que procurar um professor, e assim se tornará um "filho através do estudo" (anak murid). A universidade também é um meio de acesso ao pewayangan, a arte do wayang kulit. No entanto, para tornar-se dalang, o estudo iniciado na universidade deverá ser articulado com o aprendizado chamado "tradicional", isto é, junto a um dalang. Ao se lembrar do início de sua aprendizagem em família, I Ketut Kodi se recorda de momentos ligados às histórias que lhe eram contadas na hora de dormir:

Quando eu era criança, meus avós me contavam histórias quando eles me colocavam na cama. Desde essa época, eu já chorava com as histórias das pessoas que eram muito pobres. Eu já entendia a natureza dessas histórias. Além das histórias dos raja [reis], eles me contavam também as histórias do teatro de sombras, do wayang, já que meu avô era escultor de marionetes. Twalen e Merdah, os personagens cômicos do wayang, eu já os conhecia. Foi dessa forma que eu aprendi as histórias do topeng e do wayang. Talvez tenha sido graças a esse conhecimento transmitido pelo meu avô que eu me tornei um Penasar (Foley; Sedana, 2005, p. 201) ${ }^{28}$.

\footnotetext{
27 "Your teacher offers you a model with standard dialogue and scenes, but you must learn how to adapt these to the myriad lakon in the repertoire. You pick up hints from watching your teacher and other dalang, but the actual working out of the story and its successful performance depend on your own skill and creativity." (Tradução nossa)

28 "When I was young I was told stories by my grandparents whenever they put me to sleep, and I would already cry with the tales of the people who were poor. So I already understood the nature of narrative. Besides the stories of the raja (kings), they would tell me stories of the shadow puppet theatre, the wayang, since my grandfather was a maker of puppets. So for example, Twalen and Merdah - which shadow puppet clown was which - I knew. Therefore, I learned stories of both topeng and wayang. Maybe I was drawn to become a penasar, a topeng clown, because of this knowledge I got from my grandfather." (Tradução nossa)
} 
I Ketut Kodi foi um anak murid que teve diversos professores ${ }^{29}$ de wayang kulit. Um deles foi I Made Kredek, o pai de Ni Nyoman Candri. Kodi fala da importância dos objetos que seus professores the deram, como um lontar (livro em folha de palmeira) que Pak Rajeg lhe deu pouco antes de morrer (Foley; Sedana, 2005, p. 204). Para Kodi, encontrar seu professor e abraçá-lo é uma forma de aprendizagem, pois em Bali, o toque é entendido como uma ação dotada de poder de transferência de conhecimento, não apenas na dança, mas também no wayang kulit.

Uma das poucas e primeiras mulheres a ser instruída no wayang, Ni Nyoman Candri descreve o início do seu interesse por essa arte:

Em 1979, fiquei muito triste com a morte de meu pai. Não sabia o que aprender, nem onde. Finalmente, eu fiquei com vontade de aprender as marionetes. Nyoman Danreng de Sukawati me ensinou os wayang empat, as quatro marionetes: Malen "a voz grave", Merdah "a pequena voz", Dalem "o rei", o Sangut, o "doente". Eu aprendi essas quatro vozes. (Ladeira, 2016, p. 437)

No entanto, Ni Nyoman Candri já era uma das mais famosas intérpretes de arja e cantora reconhecida em toda Bali, por ter trabalhado durante anos na Radio Republik Indonesia (RRI). Ela relata como aprendeu a cantar com seu pai, I Made Kredek, dançarino da corte de Klungkung:

Eu aprendi a cantar depois de ter mestria no legong e no baris. Foi o meu pai que me ensinou a cantar. Os ensaios eram no rio. Entrávamos no rio cantando alto. Todos os dias eu treinava até à exaustão. Meu pai dizia: "Continue, continue, continue a cantar" (Ladeira, 2016, p. 435-436) ${ }^{31}$.

O fato de possuir um trabalho vocal elaborado facilitou muito o seu aprendizado do wayang kulit. As cerimônias balinesas são caracterizadas por uma polifonia harmônica e orquestrada, uma profusão de eventos onde cada participante tem o seu momento de ação e espera. O conceito de beleza em Bali (ramé), relaciona-se a essa multiplicidade e profusão de ações e sons. Assim, a mestria vocal do performer, seja dalang, seja ator-dançarino de topeng, é fundamental e constitui um aspecto de base em sua formação. O performer deve ter uma voz aguda, média e grave, além de saber deslocá-la com facilidade, articulando-a com o diálogo (ucap). Para isso, o treinamento vocal pode ser intenso, como nos relata Ni Nyoman Candri neste outro trecho de sua entrevista:

\footnotetext{
29 Dentre os professores de I Ketut Kodi na Academia de Artes de Denpasar estão: I Nyoman Rajeg e seu filho Pak Sumandhi, Pak Wija, Pak Mawa, Pak Dewa Sayang, Ida Bagus Sarga e Pak Persib. No chamado aprendizado "tradicional", ele teve como professores alguns dalang de Sukawati, cidade que tem uma boa reputação pelo wayang kulit: Pak Wayan Nartha e Pak Ganjareng. Também foi seu professor Pak Sidja do vilarejo de Bona, Gianyar.

30 “En 1979, la mort de mon père m'a attristé, car je ne savais pas quoi apprendre, ni où. Finalement, j'ai eu envie d'apprendre les marionnettes. Nyoman Danreng de Sukawati m'a appris les wayang empat, les quatre marionnettes: Malen, «la voix grave », Merdah, « la petite voix », Dalem, « le roi», Sangut, « le malade ». Je n'ai appris que ces quatre types de voix." (Tradução nossa)

31 "J'ai appris à chanter après avoir maîtrisé le legong et le baris. C'est mon père qui m'a appris à chanter, la répétition avait lieu dans la rivière. On se trempait dans la rivière en chantant à haute voix... On chantait comme je vous montre là (elle chante). Tous les jours, on s'entraînait jusqu'au vomissement. Mon père disait « Allez, allez, continue à chanter », jusqu'à l'épuisement." (Tradução nossa)
} 
Todos os dias, eu treinava a voz grave e a voz pequena. Em seguida, eu comecei a falar algumas palavras, palavras duras, palavras doces, sem as marionetes. Antes de tudo, aprendemos a cantar. Depois, a cantar até que a voz desapareça e apareça. (Ladeira, 2016, p. 438) ${ }^{32}$

\section{O trabalho vocal do dalang}

No wayang kulit e na quase-totalidade das formas espetaculares balinesas, os personagens são arquétipos, que encontram uma correspondência transversal nos personagens que compõem as diversas formas espetaculares. Dessa maneira, em termos de conduta do personagem, o Arjuna do wayang kulit pode encontrar uma correspondência no príncipe Panji, do gambuh, ou no topeng Dalem, no topeng. Desse modo, parte da aprendizagem do repertório vocal acontece no próprio dia-a-dia dos balineses, acompanhando e assistindo as apresentações que acontecem em toda a ilha, a todo momento: as vozes dos personagens são arquetípicas e já conhecidas por todos. A noção de atuação ou jogo do "personagem" é expressa em balinês pelo termo masolah, que pode ser compreendido como "conduta" ou "caráter". O performer busca a sua despersonalização total e a fusão completa com o personagem vivenciado. $O$ espectador não pode perceber de forma alguma quem é o marionetista que manipula a marionete ou o ator-dançarino que está por trás da máscara.

O aprendizado da conduta/caráter dos personagens passa necessariamente pela aprendizagem das vozes e do repertório vocal destes. Ao descrever o aprendizado das vozes (suara) do wayang kulit, Ni Nyoman Candri expõe o processo de ensino-aprendizagem da "conduta" dos personagens:

Quando aprendemos os wayang empat, as quatro marionetes, começamos pelo Malen. Não devemos imitar ou ver outros professores, mas sobretudo o nosso. Quando aprendemos a voz do Malen, o olhar se fixa e devemos nos concentrar no Malen. Se, por exemplo, eu o posiciono de maneira equivocada, nosso professor não aprovará. Foi assim que eu aprendi como elevar e baixar a voz até tossir. Coça aqui (ela aponta a garganta). Eu fui ensinada a falar e a comunicar com esses personagens depois de ter a mestria dessas quatro vozes. Depois, temos os textos em kawi e em seguida, as marionetes nos sãos confiadas. (Ladeira, 2016, p. 438) ) $^{33}$

Além do aprendizado do canto, o aprendizado das vozes (suara) dos personagens acontece em concomitância com a exposição dos gestos, ações e danças destes. Por exemplo, o termo singgih diz respeito à gestualidade com a qual as marionetes se dirigem às personagens mais velhas. A gestualidade dos mais velhos para com os mais novos parte sempre de cima para baixo. Os corpos dos mais jovens se curvam diante desse movimento. Os mais novos também imitam as expressões dos mais velhos, caso eles estejam contentes ou aflitos (Ladeira, 2016, p.438).

\footnotetext{
32 "D’abord, tous les jours, la voix grave et la petite voix. Ensuite, j'ai commencé à apprendre à parler des petits mots, des mots doux, des mots durs, sans les marionnettes. On apprend premièrement à chanter. Après cela, j'ai appris jusqu'à faire disparaitre la voix (elle nous le montre) puis la voix est revenue." (Tradução nossa)

33 "Quand on apprend les wayang empat, les quatre marionnettes, on commence par Malen. II ne faut pas que l'on imite ou regarde les gens, mais plutôt notre professeur. Lorsqu'on apprend la voix de Malen, le regard se fixe et doit se concentrer vers Malen. Par exemple, si on se positionne dans un endroit, et Malen est placé dans un endroit opposé, notre professeur sera en désaccord. On m’a appris comme ça. Comment augmenter et baisser la voix jusqu'à ce que je tousse. Cela gratte ici. On m'a appris à parler et à communiquer après la maîtrise de ces quatre voix. Pour résumer, voici les paroles kawi. Ensuite, on nous confie des marionnettes." (Tradução nossa)
} 
Em minhas aulas com Ni Nyoman Candri, por exemplo, começávamos pelo exercício (latihan) dos tembang macapat e em seguida trabalhávamos as vozes dos personagens do wayang kulit ${ }^{34}$. Os tembang macapat são versos e canções do repertório do arja. Durante o aprendizado vocal, o aluno também começa a experimentar como "administrar as energias" (ngunda bayu), como explica I Ketut Kodi ao descrever o treinamento vocal do performer. É preciso ter consciência do momento de inspirar, reter e expirar. Esse é um dos aspectos do ngunda bayu, que inclui o domínio da técnica e dos sentimentos ou "rasa" (Ladeira, 2016, p. 429). Segundo alguns autores balineses e estrangeiros, este conhecimento é intimamente ligado à capacidade de transformação e de encarnação do performer. Esta noção também se relaciona com a de taksu, termo de significação ampla, que varia de uma localidade à outra e de um contexto a outro, mas que pode ser compreendido como o "carisma cênico".

Abordamos neste artigo algumas das questões técnicas presentes no aprendizado do wayang kulit, principalmente aquelas relacionadas ao trabalho vocal do aprendiz. A complexidade deste processo ensino-aprendizagem não se encerra neste artigo, que esperamos ser um convite à descoberta dessa arte.

\section{Referências}

BASSET, Catherine. Musiques de Bali à Java: l'ordre et la fête. Arles: Cité de la musique e Actes sud, 1995.

BASSET, Catherine. Au-delà des apparences : morphologie des esthétiques et cosmologie à Bali. Le Banian, Paris, p.63-107, 2010.

BASSET, Catherine; PICARD, Michel. Bali: l'ordre cosmique et la quotidienneté. Paris: Éd. Autrement, 1993.

COVARRUBIAS, Miguel. Island of Bali. Singapore: Periplus Editions, 2008.

DEBOER, Frederik. Pak Rajeg's Life in Art. The Drama Review: TDR, Cambridge, vol. 23, n², pp. 57-67, jun. 1979.

DIBIA, I. W; BALLINGER, Rucina; ANELLO, Barbara. Balinese dance, drama \& music: a guide to the performing arts of Bali. Tokyo: Tuttle, 2004.

FOLEY, Kathy; SEDANA, I Nyoman. Balinese Mask Dance from the Perspective of a Master Artist: I Ketut Kodi on "Topeng". Asian Theatre Journal, San-Francisco, vol. 22, $n^{\circ} 2$, p. 199-213, 2005.

HOBART, Angela. Dancing shadows of Bali. Londres: KPI, 1987.

\footnotetext{
34 No vídeo La transmission du répertoire vocal balinais: l'expérience d'une apprentie étrangère (Coelho, 2018), apresento alguns trechos das minhas aulas com Ni Nyoman Candri. Elas aconteceram em sua residência, no vilarejo de Singapadu, em 2011. Num primeiro momento, trabalhamos cantos tradicionais balineses, tembang macapat, e em seguida, algumas vozes fortes (keras) e doces (manis) de personagens do wayang kulit. Disponivel em: <https://vimeo.com/ user81990353>. Acesso em: 1 de jul. 2018.
} 
HOOYKAAS, Christiaan. Kama and Kala, Materials for the Study of Shadow theatre in Bali. Amsterdam/London: North-Holland Publishing Company, 1973.

HOOYKAAS, Christiaan. Religion in Bali. Leiden: BRILL, 1973.

LADEIRA, Juliana Coelho de Souza. Entre mondes: voyages récits et entrelacements de pratiques autour du topeng balinais. Saint-Denis, 2016. Tese (Doutorado em Artes) - EDESTA, Université Paris 8.

PICARD, Michel, Polyglossie et vernacularisation à Bali: 'l'indianisation' par le théâtre, In: BOUVIER, Hélène (Org.) Théâtres d'Asie à l'oeuvre. Paris: EFEO, 2012.

SEDANA, I Nyoman; FOLEY, Kathy. The Education of a Balinese Dalang. Asian Theatre Journal, San-Francisco, vol. 10, n¹, p. 81-100, 1993.

SPIES, Walter; DE ZOETE, Beryl. Dance \& drama in Bali. Hong Kong: Periplus Editions, 2002.

\section{Referências audiovisuais}

COELHO, Juliana. La transmission du répertoire vocal balinais: l'expérience d'une apprentie étrangère. Incertain Regards, Cahiers dramaturgiques, França, Hors Série n², 2018. Disponível em: <https://vimeo.com/user81990353>. Acesso em: 01 de jul. 2018.

GENERATIONS OF SHADOWS. Bali Shadow Puppets. Programa que mostra algumas imagens do processo de confecção das marionetes do wayang kulit e um breve depoimento do escultor I Wayan Kurdana. Disponível em: <https://www.youtube. com/watch?v=7TvLsyek1SE>. Acesso em: 01 jul. 2018.

WAYANG KULIT / SHADOW PUPPET THEATRE. Registro de uma apresentação de wayang kulit na cidade de Ubud, com os dalang I Made Gender e I Ketut Pasek. Disponível em: <https://www.youtube.com/watch?v=CRdWhZJUGkA>. Acesso em: 01 jul. 2018.

WAYANG KULIT/ SHADOW PLAY/ THÉÂTRE D'OMBRES. Improvisações em inglês realizadas especialmente para a filmagem. Não se trata de uma apresentação do repertório tradicional do wayang kulit. Disponível em: <https://www.youtube.com/ watch?v=U6eD17MqRwE>. Acesso em: 01 jul. 2018.

WAYANG ARJA. Curta-metragem sobre o wayang arja, contado pelo dalang I Made Sidja. Disponível em: <https://www.youtube.com/watch?v=apc-8EYuG6I>. Acesso em: 01 de jul. 2018. 
BALI GO LIVE. Stories of Balinese Wayang Maestro "I Made Sidja". Programa web. O marionetista I Made Sidja disserta sobre sua história. Disponível em: <https://www. youtube.com/watch?v=Ad3INKDyOrg>. Acesso em: 01 de jul. 2018.

\section{Documentos iconográficos em meio eletrônico}

GESSEL, W.L.J. Van. Wayang kulit voorsterlling in de puri, een avond voorafgaand aan de crematie van Cokorda Gede Agung Sukawati [1979]. Disponível em: <https://hdl. handle.net/20.500.11840/485443>. Acesso em: 01 jul. 2018.

HUDSON, Alfred. Photograph of painting of Balinese wayang kulit [1860-1969?]. 1 fotografia, p\&b. Disponível em: <https://digitalcollections.nypl.org/items/510d47dc-4aa2-a3d9-e040-e00a18064a99>. Acesso em: 01 jul. 2018.

De poppenspeler Ida Putu Sweca uit Banjar met zijn wayang kulit poppen [1910-1925?]. 1 fotografia, p\&b. Disponível em: <https://hdl.handle.net/20.500.11840/323738>. Acesso em: 01 jul. 2018.

Kayonan. [?].1 fotografia, color. Disponível em: <https://commons.wikimedia.org/ wiki/File:Unidentified,_Wayang_Kulit,_Bali_-_Museu_do_Oriente_-_Lisbon,_Portugal_-_DSC06827.JPG>. Acesso em: 01 jul. 2018.

Wayangfiguur voorstellende Subadra, de demalin van Arjurna [?].1 fotografia, color. Disponível em: <https://hdl.handle.net/20.500.11840/181131>. Acesso em: 01 jul. 2018.

Wayangfiguur voorstellende Boma, zoon van Wisnu [?].1 fotografia, color. Disponível em: <https://hdl.handle.net/20.500.11840/181127>. Acesso em: 01 jul. 2018.

Wayangfiguur voorstellende de clown en bediende Twalen [?].1 fotografia, color. Disponível em: <https://hdl.handle.net/20.500.11840/181174>. Acesso em: 01 jul. 2018.

Wayangfiguur voorstellende de clown en bediende Mredah [?].1 fotografia, color. Disponível em: <https://hdl.handle.net/20.500.11840/181177>. Acesso em: 01 jul. 2018.

Wayangfiguur voorstellende de clown en bediende Sangut [?].1 fotografia, color. Disponível em: <https://hdl.handle.net/20.500.11840/181178>. Acesso em: 01 jul. 2018

Wayangfiguur voorstellende de clown en bediende Delem [?].1 fotografia, color. Disponível em: <https://hdl.handle.net/20.500.11840/181179>. Acesso em: 01 jul. 2018. 